\title{
Brief version of the CAMCOG for illiterate older adults with Alzheimer's dementia
}

\author{
Versão breve do CAMCOG para idosos analfabetos com doença de Alzheimer \\ Juliana Francisca CECATO',2, Everton BALDUINO', José Eduardo MARTINELLI', Ivan APRAHAMIAN'
}

\begin{abstract}
Background: The Cambridge Cognition Examination (CAMCOG) is one of the most used cognitive assessment batteries for older adults. Objective: To evaluate a brief version of the CAMCOG for illiterate older adults (CAMCOG-BILL) with Alzheimer's dementia (AD) and healthy controls (CG). Methods: Cross-sectional case-control study with 246 illiterate older adults (AD [ $n=159]$ and CG [ $n=87$ ], composed by healthy seniors without cognitive complaints) who never attended school or took reading or writing lessons. Diagnosis of AD was established based on the NIA-AA and DSM-5 criteria. All participants were assessed with the CAMCOG by a researcher blinded for diagnosis. To assess the consistency of the chosen CAMCOG-BILL sub-items, we performed a binary logistic regression analysis. Results: Both the CAMCOG and the CAMCOG-BILL had satisfactory psychometric properties. The area under the curve (AUC) was 0.932 ( $p<0.001)$ for the original version of CAMCOG and 0.936 for the CAMCOG-BILL. Using a cut-off score of $\geq 60$ (CAMCOG) and $\geq 44$ (CAMCOG-BILL), both instruments had the same sensitivity and specificity ( 89 and $96 \%$, respectively). Conclusion: The CAMCOG-BILL may be a preferred tool because of the reduced test burden for this vulnerable subgroup of illiterate patients with dementia.
\end{abstract}

Keywords: Alzheimer Disease; Education; Neuropsychological Tests; Aging.

\section{RESUMO}

Antecedentes: O Cambridge Cognition Examination (CAMCOG) é uma das baterias de avaliação cognitiva mais usadas para idosos. Objetivos: Avaliar uma versão breve do CAMCOG para idosos analfabetos (CAMCOG-BILL) com demência de Alzheimer (DA) em comparação com controles saudáveis não demenciados (GC). Métodos: Estudo caso-controle transversal com 246 idosos analfabetos (AD [ $n=159]$ e GC [ $n=87$ ], composto por idosos saudáveis sem queixas cognitivas) que nunca frequentaram a escola ou fizeram aulas de leitura ou redação. O diagnóstico de DA foi estabelecido pelos critérios NIA-AA e DSM-5. Todos os participantes foram avaliados por meio do CAMCOG por avaliador cego, para o diagnóstico dos grupos. Para avaliar a consistência dos subitens escolhidos do CAMCOG-BILL, realizou-se uma análise de regressão logística binária. Resultados: Tanto o CAMCOG quanto o CAMCOG-BILL apresentaram propriedades psicométricas satisfatórias. A área sob a curva (AUC) foi de 0,932 ( $p<0,001)$ para a versão original do CAMCOG e de 0,936 para o CAMCOG-BILL. Usando-se uma pontuação de corte de $\geq 60$ (CAMCOG) e $\geq 44$ (CAMCOG-BILL), ambos os instrumentos tiveram a mesma sensibilidade e especificidade (89 e 96\%, respectivamente). Conclusão: O CAMCOG-BILL pode ser preferido para reduzir a sobrecarga do teste para esse subgrupo vulnerável de pacientes analfabetos com demência.

Palavras-chave: Doença de Alzheimer; Educação; Testes Neuropsicológicos; Envelhecimento.

\section{INTRODUCTION}

Educational level is an important determinant of cognitive performance ${ }^{1,2}$. More years of formal education contribute to cognitive reserve and may support coping with aging-related cognitive decline $e^{3,4,5,6,7}$. Higher intellectuality is another neuroprotective factor. Intellectually stimulant activities, e.g. traveling, reading and writing, language classes, among others, also improve cognitive abilities during life and thereby protect against aging-related cognitive decline $^{5,6}$. Thus, alterations observed in neuropsychological assessment of seniors with high educational level or high intellectuality may indicate the presence of a neurodegenerative disease ${ }^{8,911}$. However, those with low or no formal

\footnotetext{
${ }^{1}$ Faculdade de Medicina de Jundiaí, Departamento de Medicina Interna, Divisão de Geriatria, Group of Investigation on Multimorbidity and Mental Health in Aging, Jundiaí SP, Brazil.

${ }^{2}$ Universidade São Francisco, Departamento de Psicologia, Bragança Paulista SP, Brazil.

JFC (iD http://orcid.org/0000-0002-2783-772X; EB (iD) https://orcid.org/0000-0001-9310-9491; JEM (iD) https://orcid.org/0000-0003-2766-1987;

IA (iD) https://orcid.org/0000-0003-3806-7895

Correspondence: Juliana F. Cecato; Email: cecatojuliana@hotmail.com.

Conflict of interest: There is no conflict of interest to declare.

Authors' contributions: JFC: designed, collected the data and wrote the manuscript; EB: wrote the manuscript; JEM: supervised the data collection; IA: designed the study, wrote and reviewed the manuscript.

Support: Prof. Aprahamian received a level two national public grant from the National Council for Scientific and Technological Development (Ministry of Science, Technology, Innovation and Communications, Brazil).

Received on October 06, 2020; Received in its final form on January 07, 2021; Accepted on January 12, 2021.
}

\section{(cc) BY}


education may obtain false-positive results in cognitive assessment.

$\mathrm{UNESCO}^{11}$ has estimated that around 161 million older persons ( $\geq 65$ years old) are illiterate worldwide. Seven of the ten most important economically emerging countries (classified by Columbia Center on Sustainable Investment ${ }^{12}$ ) present illiteracy rates of older adults equal or higher than $20 \%$ (Morocco: 66\%; India: 55\%; South Africa: 45\%; Indonesia: 26\%; Brazil: 21\%; Turkey: 20\%; and Mexico 20\%) ${ }^{11}$. Even though in Brazil, Mexico, and Turkey these estimates showed a decreasing trend in the last 5 years, this is still a major concern considering the impact of illiteracy in autonomy and health of older adults ${ }^{11}$. As a primary phenomenon, written language skills results in a reorganization of cognition, with changes in visual and spatial perception, logical reasoning, recall strategies, improved memory skills, metalinguistic awareness, among others ${ }^{13}$. Recently, we demonstrated the influence of illiteracy and low educational level over cognitive performance among seniors, based on the results of different cognitive screening instruments, including the Cambridge Cognition Examination (CAMCOG) ${ }^{3}$.

The CAMCOG is a valid instrument to detect suspected cases of Alzheimer's disease (AD), which is the most common cause of dementia worldwide ${ }^{14,15}$. This instrument showed good accuracy in discriminating healthy individuals from $\mathrm{AD}$ patients with a sensitivity of $100 \%$ and specificity of $95 \%^{14,15}$. Even a shorter version of the battery with only half of the items (CAMCOG-R) showed a sensitivity of $98 \%$ and a specificity of $100 \%{ }^{14}$. The CAMCOG also presented good interrater reliability and internal consistency for different stages of dementia ${ }^{9,10}$. These evidences depict that the CAMCOG is a useful cognitive battery for the identification of AD cases. Nonetheless, whether the CAMCOG would be suitable for illiterate persons with suspected dementia remains unknown. While several instruments have been developed for neuropsychological testing of older adults with low or no educational background $d^{9,10,14,15,16}$, specific validation studies in illiterate samples have not been performed.

Finally, feasible and reliable instruments for diagnostic investigation of illiterate seniors with different cognitive issues are needed. Our objective was to evaluate a brief version of the CAMCOG for illiterate older adults (CAMCOG-BILL) with Alzheimer's disease (AD) and healthy controls (CG).

\section{METHODS}

\section{Study design and participants}

We conducted a cross-sectional case-control study with 246 illiterate older adults (60 to 97 years old). Illiteracy was defined as never having learned to read or write in a school environment. A convenient sample was selected from an outpatient geriatrics clinic at the Faculdade de Medicina de Jundiaí and included those with 60 years of age or older that were healthy (CG, $\mathrm{n}=87)$ or had $\mathrm{AD}(\mathrm{n}=159)$; data collection occurred between January 2015 and December 2019. The diagnosis of $\mathrm{AD}$ was made through a multidisciplinary consensus meeting according to both the NIA-AA ${ }^{17}$ and the DSM- $5^{18}$ diagnosis criteria of $\mathrm{AD}$ and major neurocognitive disorder, respectively. Severity of dementia was clinically evaluated by the Clinical Dementia Rating (CDR). The participants in the $\mathrm{AD}$ group had mild and moderate disease stages (according to CDR, stages 1 and 2). All patients received acetylcholinesterase inhibitors alone or in combination to memantine for mild and moderate $\mathrm{AD}$, respectively.

All patients were interviewed at the outpatient clinic by a team of geriatric and psychiatric specialists, physical therapists, and neuropsychologists. In order to acquire information regarding functional disability, cognition, and behavior, all patients (including controls) were asked to attend to consultation with a relative or caregiver. Laboratory (hemogram, renal and hepatic function, electrolytes, vitamin B12 and folate, TSH, free $\mathrm{T}_{4}$, and VDRL) and imaging exams (magnetic resonance or a computerized tomography of the brain if the patient had a pacemaker or claustrophobia) were done in all patients.

The participants in the CG group were completely independent for activities of daily living (ADL), had no neuropsychiatric disorder, no subjective memory complains, nor Mild Cognitive Impairment ${ }^{18}$. These patients were followed at our clinic for routine care, such as control of chronic diseases or health maintenance.

We excluded from this study participants with any kind of disorder that could compromise the neuropsychological evaluation or that would suggest another etiology for dementia other than $\mathrm{AD}$. Thus, we excluded patients with any plegia or paresis, important tremor, functional impairment in hands, severe visual or auditory impairment, any addictive disorder, any depression syndrome (Geriatric Depression Scale score $\geq 5$ points $)^{19}$, Parkinson's disease, any stroke history or those who refused to complete any of the tests. We also excluded patients with alterations in laboratorial exams (e.g., vitamin B12 and thyrotropin) that suggested reversible dementia and neuroimaging alterations (magnetic resonance) that suggested moderate microvascular ischemia (i.e., Fazekas 2 or 3 ), hydrocephalus or neoplasm. All patients agreed to participate by signing an informed consent form approved by the local Ethics Committee (protocol number: 1.012.851).

\section{Instruments and procedures}

In our routine clinical evaluation, all patients had a complete clinical, neurological, and psychiatric evaluation by geriatricians with special focus in neuropsychiatry and also by geriatric psychiatry specialists. Additionally, the Cambridge Examination of Mental Disorder of the Elderly (CAMDEX), a semi-structured interview that yields diagnostic information on neuropsychiatric disorders of late life was used ${ }^{20}$. 
A neuropsychologist conducted the cognitive and functional evaluation. The Mini-Mental State Examination (MMSE) was used as a cognitive screening test before proceeding to $\mathrm{CDR}^{21,22}$. The Geriatric Depression Scale (GDS) with 15 items $^{19}$ and the Pfeffer's Functional Activities Questionnaire (PFAQ) ${ }^{23}$ were also applied to assess depressive symptoms and ADL, respectively. The PFAQ was applied to a relative or caregiver. In a separated session, all participants were assessed with the CAMDEX and the CAMCOG by an assessor blinded for any results of previous examinations. The CAMCOG is the $\mathrm{B}$ part of the CAMDEX and includes subtests for several cognitive domains, such as memory, attention, concentration, orientation, language, abstract thinking, calculation, praxis, and perception. The multidisciplinary team responsible for the final diagnosis of dementia was blinded for the CAMCOG score $^{20}$. The CAMCOG score did not contribute to the clinical diagnosis. The MMSE, the CDR, and clinical and functional evaluations were taken into account for establishing the $\mathrm{AD}$ diagnosis.

\section{Development of the Cambridge Cognition \\ Examination - brief version for Illiterate individuals}

For the CAMCOG-BILL development, we considered the most successful subtests scored by the CG as well as excluded the subtests with most correct answers in the $\mathrm{AD}$ group. The included subtests after the correctness analysis were: motor response (to follow verbal commands); definitions (to explain the meaning of 4 sentences); figure naming (to name correctly 6 figures); verbal fluency (to verbalize the greatest number of animals in one minute); sentence repetition and writing of address; memory (remote, recent, evocation, and recognition); countdown and calculation; and orientation (temporal and spatial). The maximum score was 60 points, and the estimated duration of the test was 35 minutes in a single session.

\section{Statistical analyses}

We analyzed the data using the IBM ${ }^{\circledR}$ Statistical Package for Social Sciences (SPSS) software version 19.0. We performed normality tests (histogram analysis and KolmogorovSmirnov test), which indicated a non-parametric distribution of the CAMCOG subtests scores. Percentages and means (and standard deviation) were calculated for sex and age. We used the Mann-Whitney test to compare differences between groups for age and chi-squared test for sex. Additionally, we evaluated the correlation between cognitive tests (MMSE and CAMCOG-BILL) and PFAQ through Spearman's correlation coefficient. To assess the consistency of the CAMCOGBILL subitems of choice, we performed a binary logistic regression analysis using a stepwise forward likelihood ratio method, based on a model with all cognitive domains (language, memory, calculation, praxis, perception, orientation). Finally, we analyzed the sensitivity and specificity of cognitive tests (the CAMCOG-BILL and the original CAMCOG) using the Receiver Operating Characteristic (ROC) curve analyses. We performed this specific analysis in the MedCalc software version 15.8. We considered p-values lower than 0.05 as statistically significant.

\section{RESULTS}

The total sample presented a mean age of 79.3 years $(60$ to 97 years; standard deviation [SD]=7.3) and $76.5 \%(\mathrm{n}=189)$ were women. Table 1 shows the clinical characteristics of $\mathrm{AD}$ and CG participants. We did not find significant differences concerning age and sex. All CAMCOG sub-items were significantly different between the two groups.

Table 2 shows the correlation between the CAMCOGBILL, the MMSE, and the PFAQ. The correlation was high between the CAMCOG-BILL and the MMSE in the total sample and was moderate in the two groups. We observed a negative moderate correlation between the CAMCOG-BILL and the PFAQ in the total sample and $\mathrm{AD}$ group. The correlation between the CAMCOG-BILL and the PFAQ was also negative but weak in the CG.

We evaluated the CAMCOG-BILL sub-items through a binary logistic regression analysis using a stepwise backward likelihood ratio. Language (OR=0.617, 95\%CI 0.444-0.858; $\mathrm{p}=0.004)$, temporal orientation $(\mathrm{OR}=0.315$; $95 \% \mathrm{CI} 0.197$ $0.506 ; \mathrm{p}<0.001)$, and spatial orientation $(\mathrm{OR}=0.354 ; 95 \% \mathrm{CI}$ 0.192-0.652; $\mathrm{p}=0.001$ ) demonstrated a significant association (Table 3 ). The psychometric results showed that this proposed model had statistical significance corroborating the likelihood

Table 1. Characteristics of control group and Alzheimer disease participants.

\begin{tabular}{|c|c|c|c|c|}
\hline \multirow{2}{*}{\multicolumn{2}{|c|}{ Age (years), mean (SD) }} & CG & $A D$ & $p$-value \\
\hline & & $78.1( \pm 7.91)$ & $79.9( \pm 7.25)$ & 0.075 \\
\hline \multirow{5}{*}{ Sex } & Female & $69.6 \%$ & $79.4 \%$ & \multirow{2}{*}{0.152} \\
\hline & Male & $30.4 \%$ & $24.6 \%$ & \\
\hline & CAMCOG & $69.12( \pm 11.92)$ & $45.08( \pm 12.41)$ & $*<0.001$ \\
\hline & MMSE & $22.73( \pm 2.88)$ & $14.51( \pm 3.51)$ & $*<0.001$ \\
\hline & PFAQ & $1.30( \pm 1.57)$ & $18.36( \pm 8.64)$ & $*<0.001$ \\
\hline \multirow{7}{*}{$\begin{array}{l}\text { CAMCOG } \\
\text { subtests }\end{array}$} & Language & $10.8( \pm 1.7)$ & $8.0( \pm 1.9)$ & $*<0.001$ \\
\hline & Memory & $10.6( \pm 2.7)$ & $6.8( \pm 3.1)$ & $*<0.001$ \\
\hline & Praxis & $8.2( \pm 2.0)$ & $6.5( \pm 1.6)$ & $\star<0.001$ \\
\hline & Perception & $6.4( \pm 1.6)$ & $4.8( \pm 1.6)$ & $*<0.001$ \\
\hline & $\begin{array}{l}\text { Temporal } \\
\text { orientation }\end{array}$ & $4.2( \pm 0.8)$ & $2.0( \pm 1.4)$ & $\star<0.001$ \\
\hline & $\begin{array}{c}\text { Spatial } \\
\text { orientation }\end{array}$ & $4.6( \pm 0.5)$ & $3.0( \pm 1.3)$ & $\star<0.001$ \\
\hline & Calculate & $1.6( \pm 0.5)$ & $1.1( \pm 0.5)$ & $\star<0.001$ \\
\hline
\end{tabular}

CG: control group; AD: Alzheimer disease; CAMCOG: Cambridge Cognition Examination; MMSE: Mini-Mental State Exam; PFAQ: Pfeffer's Functional Activities Questionnaire; SD: standard deviation; CAMCOG: Cambridge Cognition Examination; * ${ }^{p}$ : Mann-Whitney. 
Table 2. Correlation analyses between Cambridge Cognition Examination brief version for Illiterate individuals and Mini-Mental State Exam and Mini-Mental State Exam for the total sample, Alzheimer disease group and control group participants.

\begin{tabular}{lccccccccc} 
& Total sample $(n)$ & rho & p-value & CG $(n)$ & rho & $p$ & $A D(n)$ & rho & $p$-value \\
\hline CAMCOG-BILL and MMSE & 246 & 0.85 & $<0.001$ & 87 & 0.70 & $<0.001$ & 160 & 0.68 & $<0.001$ \\
CAMCOG-BILL and PFAQ & 246 & -0.67 & $<0.001$ & 87 & -0.31 & 0.005 & 160 & -0.53 & $<0.001$ \\
\hline
\end{tabular}

CG: control group; AD: Alzheimer disease; MMSE: Mini-Mental State Exam; PFAQ: Pfeffer's Functional Activities Questionnaire; rho: Spearman correlation coefficient; CAMCOG-BILL: Cambridge Cognition Examination brief version for Illiterate individuals.

Table 3. Forward stepwise logistic regression of the Cambridge Cognition Examination subitems.

\begin{tabular}{llllll}
\hline \multirow{2}{*}{ Subtests } & SE & p-value & OR & \multicolumn{2}{c}{$95 \% \mathrm{Cl}$ OR } \\
\cline { 5 - 6 } & & & & Lower & Upper \\
\hline Language & 0.168 & 0.004 & 0.617 & 0.444 & 0.858 \\
Memory & 0.091 & 0.062 & 0.844 & 0.706 & 1.008 \\
\hline Countdown & 0.289 & 0.436 & 0.799 & 0.453 & 1.407 \\
\hline Praxis & 0.159 & 0.565 & 1.096 & 0.802 & 1.497 \\
\hline Calculation & 0.502 & 0.157 & 0.491 & 0.184 & 1.315 \\
\hline Perception & 0.165 & 0.126 & 0.777 & 0.563 & 1.073 \\
\hline Temporal & 0.241 & $<0.001$ & 0.315 & 0.197 & 0.506 \\
orientation & 0.311 & 0.001 & 0.354 & 0.192 & 0.652 \\
\hline Spatial orientation & 0.006 &
\end{tabular}

CAMCOG: Cambridge Cognition Examination; SE: standard error; OR: Odds Ratio; 95\% Cl: 95\% confidence interval.

value (Model Likelihood) found in the regression analysis $(\mathrm{p}<0.001)$ with a predictive value of $83.3 \%$. We performed another forward stepwise logistic regression for the memory subtests considering that the CAMCOG's memory sub-item was not significant $(p=0.062)$ and the memory impairment is a cornerstone cognitive dysfunction in $\mathrm{AD}$ (Table 4). The recent memory subtest $(\mathrm{OR}=0.444 ; 95 \% \mathrm{CI} 0.335-0.589 ; \mathrm{p}<0.001)$ and the memory recall $(\mathrm{OR}=0.746 ; 95 \% \mathrm{CI} 0.602-0.923 ; \mathrm{p}=0.007$ ) were significant for $\mathrm{AD}$ identification.

The area under the curve (AUC) of ROC for the original CAMCOG and the CAMCOG-BILL were similar and significantly discriminated between cases and controls (Figure 1). The original CAMCOG presented a cut-off value of equal or less than 60 points for $\mathrm{AD}$ (AUC=0.936, standard error $[\mathrm{SE}]=0.015)$. The cut-off score for the CAMCOG-BILL was equal or less than 44 points $(\mathrm{AUC}=0.932$, standard error $[\mathrm{SE}]=0.016)$. Both instruments showed high sensitivity and specificity values ( 89 and $96 \%$, respectively).

\section{DISCUSSION}

To the best of our knowledge, this is the first study to evaluate a shorter version of the CAMCOG adapted to illiterate groups of $\mathrm{AD}$ patients and cognitively healthy older adults. The subtests of the CAMCOG-BILL included the items assessing temporal and spatial orientation, recent memory,
Table 4. Forward stepwise logistic regression of the Cambridge Cognition Examination memory subtests.

\begin{tabular}{lccccc}
\hline \multirow{2}{*}{$\begin{array}{l}\text { Subtests } \\
\text { Recent memory }\end{array}$} & SE & p-value & OR & \multicolumn{2}{c}{$95 \% \mathrm{ClOR}$} \\
\cline { 5 - 6 } & & & & Lower & Upper \\
\hline $\begin{array}{l}\text { Memory recall } \\
\begin{array}{l}\text { Memory } \\
\text { recognition }\end{array}\end{array}$ & 0.109 & 0.007 & 0.746 & 0.602 & 0.923 \\
\hline
\end{tabular}

CAMCOG: Cambridge Cognition Examination; SE: standard error; OR: Odds Ratio; 95\%Cl: 95\% confidence interval.

memory recall, and language of the original $\mathrm{CAMCOG}$ scale. The original CAMCOG and the CAMCOG-BILL presented good psychometric properties to assess these patients, significantly discriminating the two groups. Both instruments showed similar diagnostic accuracy with the same sensitivity and specificity, and a cut-off of less than 44 points in the CAMCOG-BILL is suggested to differentiate $\mathrm{AD}$ patients from controls.

The CAMCOG is a sensitive battery and widely used to assess different levels of cognitive impairment in older adults ${ }^{9,10,15,16,24,25}$. However, CAMCOG's cut-off score appears to be affected by age and education level, and performance may be modulated by sociodemographic characteristics ${ }^{23}$. Therefore, there is a need for adapting this instrument for use in the oldest old or individuals with little formal education. Previously, a cut-off score of 65 points was proposed for a sample of illiterate healthy seniors with more than 80 years ${ }^{3}$, and lower performance, especially in memory, praxis, and abstraction subtests, was described for seniors with 90 years or more ${ }^{26}$. Since its description, the CAMCOG battery showed cut-off scores that increased with higher educational levels ${ }^{23}$. In a previous study evaluating the association between sociodemographic variables and CAMCOG scores, educational level influenced language and abstract thinking scores $^{27}$. In another Brazilian study, memory, language, visual perception, and abstract thinking distinguished three different levels of education ${ }^{28}$, but illiterates were not included. In our study, all CAMCOG subtests were significantly different between the two groups. Aprahamian et al. reported a cutoff score of 79 points for older adults (mean age 75.7 years) with low educational level (1 to 4 years of formal education), with sensitivity of $88 \%$ and specificity of $83 \%$ for detecting mild $\mathrm{AD}^{16}$. Moreover, in a sample of older adults from low 

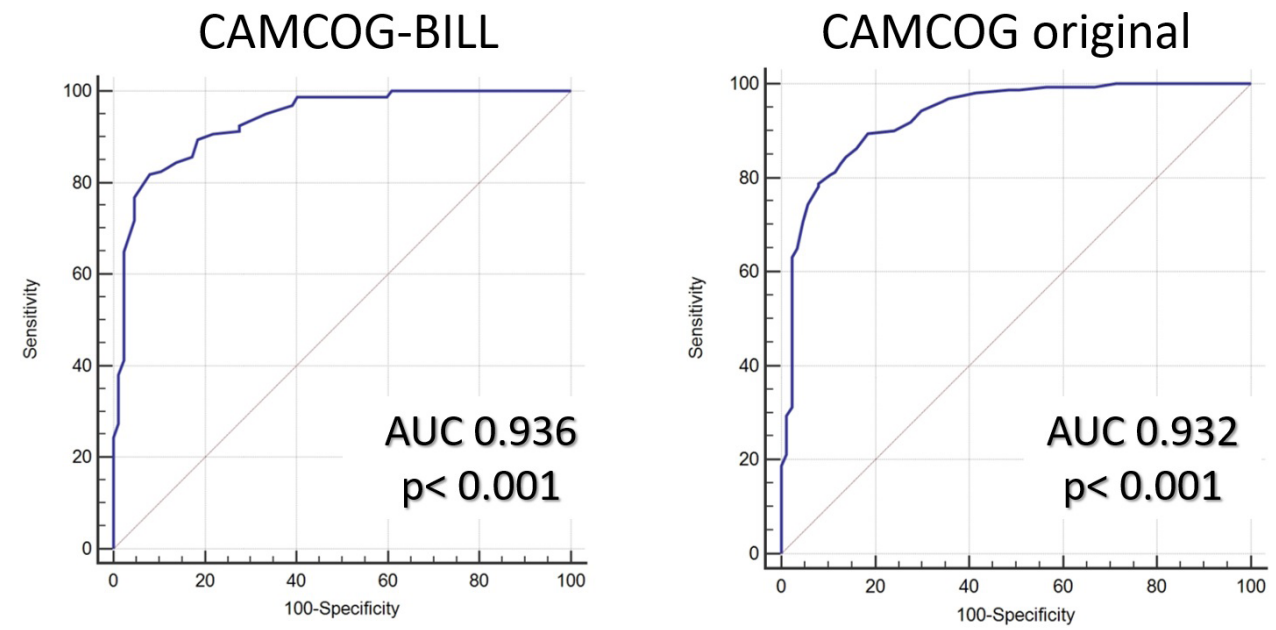

ROC: receiver operating characteristic; AUC: area under the curve; CAMCOG: Cambridge Cognition Examination; CAMCOG-BILL: Cambridge Cognition Examination brief version for Illiterate individuals.

Figure 1. ROC curves, AUC, and accuracy values for the original Cambridge Cognition Examination and the Cambridge Cognition Examination brief version for Illiterate individuals.

to middle-income countries, CAMCOG's language subtests were highly affected by educational level ${ }^{28}$. Finally, a previous study compared CAMCOG scores of 189 low-educated Brazilian older adults with dementia to those of healthy controls ${ }^{10}$. Most participants were illiterate (mean educational level of $3.1 \pm 2.2$ years). The best cut-off score to discriminate between dementia and control groups was 50/51 with a sensitivity and specificity of $69 \%$. The cut-off value of 44 was established for proposed CAMCOG-BILL, but the scale had different AUC (0.936 versus 0.750) and diagnostic accuracy values (69 versus $89 \%$ sensitivity and $96 \%$ specificity) than the original scale.

Several arguments could explain these differences such as the strict diagnostic criteria in this study to include only $\mathrm{AD}$ patients and the use of an adapted brief version of the CAMCOG without language constraints for illiterate seniors. Furthermore, another important characteristic of our sample is that it was entirely composed of illiterate people, i.e., never attended school, learned to read or write, or attended supplementary school or similar programs to compensate for the absence of formal education in childhood.

Brief versions of the CAMCOG can be of high clinical value and save time when assessing mild cognitive impairment and early dementia ${ }^{16}$. Previously, some of the CAMCOG's subtests were shown to have better discrimination ability of mildly impaired older adults and controls than the total score, in both cross-sectional and longitudinal studies ${ }^{16,29,30,31}$. Orientation and memory subtests, especially delayed recall, are more implicated with $\mathrm{AD}$ than other sbtests ${ }^{16,29,30,31}$. Most of the CAMCOG-BILL items assess orientation and memory outcomes, which could explain the high AUC and diagnostic accuracy in $\mathrm{AD}$ patients. Even among older adults with cerebrovascular disease (e.g. carotid occlusion and history of brain stroke) but not dementia, orientation (OR=2.25; 95\%CI 1.40-3.61), language $(\mathrm{OR}=1.80$; 95\%CI $1.10-2.95)$, memory $(\mathrm{OR}=1.67$; 95\%CI 1.05-2.65), perception (OR=1.74; 95\%CI 1.02-2.98), and praxis $(\mathrm{OR}=1.64$; $95 \% \mathrm{CI} 1.03-2.62)$ were more frequently impaired and associated with vascular dementia after 2 years of follow-up ${ }^{25}$. Additionally, brief versions of the CAMCOG could be used as alternatives to other brief cognitive tests such as the Mini Mental State Examination, the Addenbrooke test, and the Rowland Universal Dementia Assessment Scale (RUDAS). Of these scales, the first two have adapted scores for people with low educational level or illiterate, and thus require more in-depth evaluation for illiterate patients with dementia ${ }^{32,33}$. The RUDAS is designed for patients with low educational background but presents specific cut-off scores for different populations ${ }^{34}$.

Formal education has a strong effect on the construction of cognitive reserve, and elderly with higher educational level received more brain stimuli contributing to a greater cognitive reserve and consequently, decreasing their risk of dementia $^{1,2,3}$. In fact, several studies demonstrated that a few years of formal education might elicit better cognitive performance, owing to the neurocognitive development and brain network reorganization ${ }^{35,36,37,38,39}$. As there are approximately eight hundred million illiterate people in the world, the interpretation of the cognitive performance in traditional neuropsychological tests, which are developed to assess the literate population, can be a challenge ${ }^{7}$. Our study presented valid psychometric data indicating that the CAMCOG-BILL has adequate sensitivity and specificity to assess illiterate elderly with possible AD. Our instrument also presented convergent validity compared to the MMSE (a similar cognitive instrument), with the tools presenting significant and robust correlations. The original CAMCOG has a broad applicability but it is time-consuming and illiterate seniors might be unfamiliar with subtests because of reading, writing, calculating, and abstract thinking impairments. CAMCOG-BILL 
demonstrated high sensitivity for the assessment of memory, language, and orientation, whilst demanding less time to be completed, keeping the patients motivated throughout the test. In fact, maintaining the focus of older adults during an entire neuropsychological session is a challenge. Leite et al. ${ }^{40}$ used a brief version of a cognitive instrument for illiterate seniors and found that the attention of the participants was maintained throughout the assessment ${ }^{40}$. In clinical practice, the results of such tests in older adults with low or no formal education can indicated a false mild dementia because most instruments need reading and logical thinking abilities. In our region, for example, the percentage of illiteracy among older adults is $9.7 \%^{41}$, which is an important reason for the development of cognitive instruments adapted for this population.

Some potential limitations of this study must be addressed. The CAMCOG-BILL might still be too complex for illiterate people to understand as the original CAMCOG was not developed specifically for this population. Moreover, the ecological validity of the CAMCOG-BILL has not been assessed and its verisimilitude and veridicality need to be explored in future studies to consolidate the use of this instrument for this specific and cognitively complex population. Adjusting some items may further increase the tool's specificity. Furthermore, we did not evaluate other components of cognitive reserve beyond years of education, such as intelligent coefficient, occupational status, engagement in leisure activities, and the strength of social relationships. Illiteracy results in a complex heterogeneous cognitive reserve and cannot be fully characterized based on years of schooling alone. Our research is a case-control study, which used a convenient sample of illiterate seniors from our specialized clinic. Moreover, information regarding multimorbidity, frailty, and prescription drugs was not collected, which could better characterize the sample. Additionally, we included only older adults with $\mathrm{AD}$ and more studies are recommended to assess the properties of the CAMCOG-BILL in people with other cognitive disorders. Finally, cognitive performance in illiterate people is heterogeneous and samples from different regions of our country and abroad may show different results.

In conclusion, the present study showed that the CAMCOG-BILL is a feasible instrument for the evaluation of illiterate people with suspected $\mathrm{AD}$. The instrument showed high accuracy in diagnosing $\mathrm{AD}$, close to that of the original CAMCOG battery, but the verbal responses, the reading, and the perception sub-items of the original CAMCOG were removed.

\section{ACKNOWLEDGEMENT}

We thank Prof Richard C. Oude Voshaar for his kind review of the final version of the manuscript.

\section{References}

1. Fritsch T, McClendon MJ, Smyth KA, Ogrocki PK. Effects of educational attainment and occupational status on cognitive and functional decline in persons with Alzheimer-type dementia. Int Psychogeriatr. 2002 Dec;14(4):347-63. https://doi.org/10.1017/ s1041610202008554

2. Lee WJ, Liang CK, Peng LN, Chiou ST, Chen LK. Protective factors against cognitive decline among community-dwelling middle-aged and older people in Taiwan: A 6-year national population-based study. Geriatr Gerontol Int. 2017 Apr;17 Suppl 1:20-7. https://doi. org/10.1111/ggi.13041

3. Balduino E, Melo BAR, Sousa LSM, Martinelli JE, Cecato JF. The "Superagers" construct in clinical practice: neuropsychological assessment of illiterate and educated elderly. Int Psychogeriatr. 2019 Sep;32(2):191-8. https://doi.org/10.1017/ S1041610219001364

4. Kremen WS, Beck A, Elman JA, Gustavson DE, Reynolds CA, Tu $\mathrm{XM}$, et al. Influence of young adult cognitive ability and additional education on later-life cognition. Proc Natl Acad Sci U S A. 2019 Feb;116(6):2021-6. https://doi.org/10.1073/pnas.1811537116

5. Livingston G, Huntley J, Sommerlad A, Ames D, Ballard C, Banerjee S, et al. Dementia prevention, intervention, and care: 2020 report of the Lancet Commission. Lancet. 2020 Aug;396(10248):413-46. https:// doi.org/10.1016/S0140-6736(20)30367-6

6. Stern Y. Cognitive reserve. Neuropsychologia. 2009 Aug;47(10):201528. https://doi.org/10.1016/j.neuropsychologia.2009.03.004

7. Julayanont P, Ruthirago D. The illiterate brain and the neuropsychological assessment: from the past knowledge to future new instruments. Appl Neuropsychol Adult. 2018 MarApr;25(2):174-87. https://doi.org/10.1080/23279095.2016.1250211

8. Barulli D, Stern Y. Efficiency, capacity, compensation, maintenance, plasticity: emerging concepts in cognitive reserve. Trends Cogn Sci. 2013 Oct;17(10):502-9. https://doi.org/10.1016/j.tics.2013.08.012

9. Paradela EM, Lopes CS, Lourenço RA. Reliability of the Brazilian version of the Cambridge Cognitive Examination Revised CAMCOG-R. Arq Neuro-Psiquiatr. 2009 Jun;67(2B):439-44. https://doi. org/10.1590/S0004-282X2009000300013

10. Paradela EM, Lourenço RA. Is the Cambridge Cognitive Examination - revised a good tool for detection of dementia in illiterate Brazilian older adults? Geriatr Gerontol Int. 2014 Oct;14(4):763-8. https://doi. org/10.1111/ggi.12161

11. UNESCO - UIS (Unesco Institute for Statistics). Education metadata from UIS Statistical. 2019 [accessed on Jun 16, 2020]. Available at: http://data.uis.unesco.org.

12. Columbia Center of Sustainable Investment. Emerging Market Global Players (EMGP). 2018 [accessed on Jun 16, 2020]. Available at: http:// ccsi.columbia.edu/files/2013/10/EMGP.pdf

13. Ardila A, Bertolucci PH, Braga LW, Castro-Caldas A, Judd T, Kosmidis $\mathrm{MH}$ et al. Illiteracy: the neuropsychology of cognition without reading. Arch Clin Neuropsychol. 2010 Dec;25(8):689-712. https://doi. org/10.1093/arclin/acq079

14. Aprahamian I, Martinelli J, Cecato J, Izbicki R, Yassuda M. Can the CAMCOG be a good cognitive test for patients with Alzheimer's disease with low levels of education? Int Psychogeriatr. 2011 Feb;23(1):96-101. https://doi.org/10.1017/S104161021000116X 
15. Nunes PV, Diniz BS, Radanovic M, Abreu ID, Borelli DT, Yassuda MS, et al. CAMCOG as a screening tool for diagnosis of mild cognitive impairment and dementia in a Brazilian clinical sample of moderate to high education. Int J Geriatr Psychiatry. 2008 Nov;23(11):1127-33. https://doi.org/10.1002/gps.2038

16. Aprahamian I, Diniz BS, Izbicki R, Radanovic M, Nunes PV, Forlenza OF. Optimizing the CAMCOG test in the screening for mild cognitive impairment and incipient dementia: saving time with relevant domains. Int J Geriatr Psychiatry. 2011 Apr;26(4):403-8. https://doi. org/10.1002/gps.2540

17. McKhann G, Knopman DS, Chertkow H, Hyman BT, Jack CR, Kawas $C$, et al. The diagnosis of dementia due to Alzheimer's disease: recommendations from the National Institute on Aging-Alzheimer's Association workgroups on diagnostic guidelines for Alzheimer's disease. Alzheimers Dement. 2011 May;7(3):263-9. https://doi. org/10.1016/j.jalz.2011.03.005

18. American Psychiatry Association. Diagnostic and Statistical Manual of Mental Disorders (DSM-5). Arlington, VA: American Psychiatric Association.; 2013.

19. Yesavage JA, Brink TL, Rose TL, Lum O, Huang V, Adey M, Leirer VO. Development and validation of a geriatric depression screening scale: a preliminary report. J Psychiatr Res. 1982-1983;17(1):37-49. https://doi.org/10.1016/0022-3956(82)90033-4

20. Roth M, Tym E, Mountjoy CQ, Huppert FA, Hendrie H, Verma S, Goddard R. CAMDEX. A standardized instrument for the diagnosis of mental disorder in the elderly with special reference to the early detection of dementia. Br J Psychiatry. 1986 Dec;149:698-709. https://doi.org/10.1192/bjp.149.6.698

21. Brucki S, Nitrini R, Caramelli P, Bertolucci P, Okamoto I. Sugestões para o uso do mini-exame do estado mental no Brasil. Arq NeuroPsiquiatr. 2003 Sep;61(3-B):777-81. https://doi.org/10.1590/S0004282X2003000500014

22. Folstein MF, Folstein SE, McHugh P. Mini-Mental State: a practical method for grading the cognitive state of patients for the clinician. J Psychiatr Res. 1975 Nov;12(3):189-98. https://doi.org/10.1016/00223956(75)90026-6

23. Pfeffer RI, Kurosaki TT, Harrah Jr CH, Chance JM, Filos S. Measurement of functional activities in older adults in the community.J Gerontol. 1982 May;37(3):323-9. https://doi. org/10.1093/geronj/37.3.323

24. Chen A, Akinyemi RO, Hase Y, Firbank MJ, Ndunq'u MN, Foster V, et al. Frontal white matter hyperintensities, clasmatodendrosis and gliovascular abnormalities in ageing and post-stroke dementia. Brain. 2016 Jan;139(Pt 1):242-58. https://doi.org/10.1093/brain/ awv328

25. Stephan BCM, Minett T, Muniz-Terrera G, Harrison SL, Matthews FE, Brayne C. Neuropsychological profiles of vascular disease and risk of dementia: implications for defining vascular cognitive impairment no dementia (VCI-ND). Age Ageing. 2017 Sep;46(5):755-60. https://doi. org/10.1093/ageing/afx016

26. Canneti B, Mosqueira AJ, Carreras T, Gago-Veiga AB, Onsurbe C, Ruiz $M$, Vivancos J. Differences in performance in CAMCOG-R domains between old and oldest old patients with Alzheimer's disease. Neuropsychol Dev Cogn B Aging Neuropsychol Cogn. 2018;25(4):58897. https://doi.org/10.1080/13825585.2017.1353679

27. Huppert FA, Brayne C, Gill C, Paykel ES, Beardsall L. CAMCOG-A concise neuropsychological test to assist dementia diagnosis: Socio-demographic determinants in an elderly population sample. Br J Clin Psychol. 1995 Nov;34(4):529-41. https://doi. org/10.1111/j.2044-8260.1995.tb01487.x
28. Moreira IFH, Bezerra AB, Sudo FK, Alves GS, Ericeira-Valente L, Tiel C, et al. CAMCOG - Valores das subescalas em idosos normais com níveis diferentes de escolaridade - Aspectos preliminares. Rev Bras Neurol. 2013 Jan-Mar;49(1):32-6.

29. James KA, Grace LK, Thomas KG, Combrinck MI. Associations between CAMCOG-R subscale performance and formal education attainment in South African older adults. Int Psychogeriatr. 2014 Nov;1-10. https://doi.org/10.1017/S1041610214002233

30. Gallagher D, Mhaolain AN, Coen R, Walsh C, Kilroy D, Belinski K, et al. Detecting prodromal Alzheimer's disease in mild cognitive impairment: utility of the CAMCOG and other neuropsychological predictors. Int J Geriatr Psychiatry. 2010 Dec;25(12):1280-7. https:// doi.org/10.1002/gps. 2480

31. Conde-Sala JL, Garre-Olmo J, Vilalta-Franch J, Llinás-Reglá J, Turró-Garriga O, Lozano Galleto M, et al. Predictors of cognitive decline in Alzheimer's disease and mild cognitive impairment using the CAMCOG: a five-year follow-up. Int Psychogeriatr. 2012 Jun;24(6):948-58. https://doi.org/10.1017/S1041610211002158

32. Aprahamian I, Martinelli JE, Neri AL, Yassuda MS. The accuracy of the Clock Drawing Test compared to that of standard screening tests for Alzheimer's disease: results from a study of Brazilian elderly with heterogeneous educational backgrounds. Int Psychogeriatr. 2010 Feb;22(1):64-71. https://doi.org/10.1017/S1041610209991141

33. Amaral-Carvalho V, Caramelli P. Normative data for healthy middleaged and elderly performance on the Addenbrooke Cognitive Examination-Revised. Cogn Behav Neurol. 2012 Jun;25(2):72-6. https://doi.org/10.1097/WNN.0b013e318259594b

34. de Araujo NB, Nielsen TR, Engedal K, Barca ML, Coutinho ES, Laks J. Diagnosing dementia in lower educated older persons: validation of a Brazilian Portuguese version of the Rowland Universal Dementia Assessment Scale (RUDAS). Braz J Psychiatry. $2018 \mathrm{Jul}$ Sep;40(3):264-9. https://doi.org/10.1590/1516-4446-2017-2284.

35. Baker DP, Salinas D, Eslinger PJ. An envisioned bridge: Schooling as a neurocognitive developmental institution. Dev Cogn Neurosci. 2012 Feb;2 Suppl 1(Suppl 1):S6-17. https://doi.org/10.1016/j. dcn.2011.12.001

36. Farfel JM, Nitrini R, Suemoto CK, Grinberg LT, Ferretti REL, Leite REP, et al. Very low levels of education and cognitive reserve: a clinicopathologic study. Neurologya. 2013 Aug;81(7):650-7. https:// doi.org/10.1212/WNL.0b013e3182a08f1b

37. Rosselli M, Ardila A, Matute E, Vélez-Uribe I. Language development across the life span: A neuropsychological/neuroimaging perspective. Neurosci J. 2014;2014:585237. https://doi. org/10.1155/2014/585237.

38. Horowitz-Kraus T, Hutton JS. From emergent literacy to reading: how learning to read changes a child's brain. Acta Paediatr. 2015 Jul;104(7):648-56. https://doi.org/10.1111/apa.13018

39. Contador I, Del Ser T, Llama S, Villarejo A, Benito-León J, BermejoPareja F. Impact of literacy and years of education on the diagnosis of dementia:A population-based study.J Clin Exp Neuropsychol. 2017 Mar;39(2):112-9. https://doi.org/10.1080/13803395.2016.1204992

40. Leite KSB, Miotto EC, Nitrini R, Yassuda MS. Boston Naming Test (BNT) original, Brazilian adapted version and short forms: normative data for illiterate and low-educated older adults. Int Psychogeriatr. 2017 May;29(5):825-33. https://doi.org/10.1017/ S1041610216001952

41. Indicadores Sociais de Jundiaí: Censo 2010, IPRS, Futuridade, IDSUS e Segurança Pública. 2010 [accessed on Jan 29, 2021]. Available at: https://transparencia.jundiai.sp.gov.br/wp-content/uploads/ relatorio_indicadores_jundiai_2012.pdf 